Revista lus et Praxis, Año 23, № 2, 2017, pp. 509 - 546

ISSN 0717 - 2877

Universidad de Talca - Facultad de Ciencias Jurídicas y Sociales

La responsabilidad civil por daños, lesiones y muerte en vuelos de instrucción dentro de Chile. Comentario a tres sentencias de la Corte Suprema Macarena Díaz de Valdés Haase

Trabajo recibido el 21 de septiembre de 2016 y aprobado el 13 de junio de 2017

\title{
La responsabilidad civil por daños, lesiones y muerte en vuelos de instrucción dentro de Chile. Comentario a tres sentencias de la Corte Suprema
}

\author{
Liability For Damages, Injuries and Death Caused by Instruction \\ FLIGHTS IN CHILE
}

Macarena díaz de Valdés HaAse*

\begin{abstract}
RESUMEN
El artículo analiza la responsabilidad civil por lesiones y muerte en accidentes ocurridos en vuelos de instrucción realizados dentro del territorio de la República. Si ha participado en el accidente un instructor de vuelo, se propone que la responsabilidad es contractual y se determina conforme a las normas del derecho supletorio general. La intervención de un inspector de vuelo, que es funcionario de la Dirección General de Aeronáutica Civil, o de otro funcionario público, abre la vía para dirigirse extracontractualmente contra el Estado, por falta de servicio. En cambio, tratándose de daños en la superficie (daños, lesiones o muerte), independientemente de la calidad funcionaria de la persona que está al mando de la aeronave y del tipo de aeronave que cause los daños, la responsabilidad se determina conforme al régimen especial en dos estratos contenido en el Código Aeronáutico. La importancia de este estudio radica en que los vuelos de instrucción no están sujetos al régimen de responsabilidad establecido por el Código Aeronáutico para los servicios de transporte aéreo, y las sentencias judiciales que se amparan en dichas normas para atribuir responsabilidad al dueño o explotador de la aeronave o al Estado se apartan del régimen legal. Los vuelos de instrucción realizados por clubes aéreos no están amparados por un seguro obligatorio que haga comercialmente viable el funcionamiento de un régimen como el del transporte aéreo. La obligación de tener seguro sólo alcanza a la aeronáutica comercial.
\end{abstract}

\section{Introducción}

El objeto de este estudio es el régimen al que se sujeta la responsabilidad civil por daños, lesiones y muerte por accidentes en vuelos de instrucción. El trabajo analiza tres casos resueltos por la Corte Suprema de Chile por causa de accidentes en vuelos de instrucción ocurridos dentro del territorio de la República, con resultado de daños, lesiones o muerte. La cuestión es determinar cuál es el régimen de responsabilidad aplicable en aquellos casos en que el accidente se produce por la negligencia del instructor o del inspector de vuelo,

\footnotetext{
* Abogada. Becaria Conicyt en el programa de doctorado de la Universidad de los Andes (Santiago de Chile). Correo electrónico: mdiazdevaldes@miuandes.cl.
} 
este último funcionario dependiente de la Dirección General de Aeronáutica Civil (en adelante, también DGAC). En este último caso, la pregunta es si el accidente podría alcanzar la responsabilidad civil del Estado por falta de servicio, o si, por el contrario, la legislación establece otro centro de imputación de esta responsabilidad. Esto exige analizar las normas del Código Aeronáutico (en adelante, también CA), la función y atribuciones de los distintos actores que intervienen en la actividad aeronáutica, especialmente, en los vuelos de instrucción (el instructor de vuelo, el inspector de vuelo, el alumno), y la naturaleza de estos vuelos desde el punto de vista de la teoría general del contrato.

Las aeronaves se dividen en aeronaves de Estado y aeronaves civiles (artículo 29 CA). Las aeronaves civiles son aquellas aeronaves distintas a las aeronaves militares y a las destinadas a servicios de policía o de aduana (artículo 30 CA), aunque pertenezcan a organismos, servicios o empresas del Estado, a las municipalidades o al Fisco (artículo 31 CA). Éstas, a su vez, se dividen en aeronaves de uso comercial y aeronaves de uso no comercial o privado.

Frente a un mismo hecho dañoso sufrido a bordo de una aeronave civil, pueden aplicarse diferentes regímenes de responsabilidad dependiendo del caso concreto de que se trate. Si los daños ocurren a bordo de una aeronave civil de uso comercial, en primer lugar, se debe distinguir si ésta realiza servicios de transporte aéreo u otros trabajos aéreos. Si la aeronave realiza un trabajo aéreo (artículo 95 CA) y éste consiste en un vuelo de instrucción (Reglamento sobre Operación de Aeronaves, en adelante también Reglamento DAR-061), se debe, en segundo lugar, determinar si en dicho vuelo participa un instructor de vuelo (Reglamento sobre licencias al personal aeronáutico, en adelante también Reglamento DAR-012) o el accidente tuvo lugar durante el examen que se rinde ante un inspector de vuelo. Se defiende la hipótesis de que la responsabilidad por los daños, lesiones o muerte causados por el accidente a bordo de una aeronave durante un vuelo de instrucción debe determinarse conforme a las normas del derecho común contractual si el accidente se debe a la negligencia del instructor de vuelo (artículos 1545 y siguientes del Código Civil, en adelante también CC), o extracontractual (artículos 2314 y siguientes CC) si el accidente se debe a la negligencia del instructor de vuelo que tenga el carácter de funcionario público o del inspector de vuelo. No es aplicable a los vuelos de instrucción el régimen de responsabilidad especial, en dos estratos, regulado en el Título IX del Código Aeronáutico (artículos 142 a 175 CA), salvo por daños causados a terceros en la superficie.

1 D.S. [Defensa] No 52, de 2002.

${ }^{2}$ D.S. [Defensa] No 51, de 2004. 
Si los daños, en cambio, ocurren a bordo de una aeronave civil de uso privado o no comercial, también debe aplicarse el régimen común de responsabilidad contractual contenido en el Código Civil cuando el alumno del vuelo de instrucción es socio del club aéreo (artículo 94 CA).

Distinto es el régimen aplicable si los daños son sufridos por terceros en la superficie a causa de una aeronave o de lo que de ella cae o se desprende. En estos casos debe aplicarse siempre el mismo régimen de responsabilidad contemplado en el Capítulo II del Título IX del Código Aeronáutico (artículo 155 y siguientes CA), sin importar si la aeronave civil es de uso comercial o no comercial, o la calidad del piloto al mando del vuelo. La única excepción es que se trate de una aeronave del Fisco destinada a Carabineros de Chile para el ejercicio de sus funciones propias. Conforme a lo dispuesto en el artículo $3^{\circ}$ inciso $2^{\circ} \mathrm{CA}$, estas aeronaves quedan excluidas del régimen especial de responsabilidad del Título IX del Código Aeronáutico. En todos estos casos existe un cúmulo de regímenes (salvo en el de Carabineros de Chile), pudiendo la víctima optar entre el régimen especial de responsabilidad consagrado en el Código Aeronáutico para daños a terceros en la superficie o el régimen común de responsabilidad.

El estudio se presenta de la siguiente manera. En la $\S 2$ se ofrece un análisis de los casos recientemente fallados por los tribunales chilenos para ilustrar los problemas prácticos que justifican este trabajo. La $\S 3$ aborda la cuestión de si la responsabilidad especial del Código Aeronáutico es o no aplicable a los vuelos de instrucción, sugiriendo una respuesta negativa a esta pregunta. La $\S 4$ sistematiza el régimen de responsabilidad aplicable al explotador por los daños sufridos por el alumno a bordo de la aeronave durante un vuelo de instrucción y analiza la posible aplicación de la responsabilidad del Estado por falta de servicio; y la $\S 5$ aborda la normativa especial de la acción por daños, lesiones o muerte causados a terceros en la superficie por una aeronave o de lo que ella cae o se desprende.

\section{Tratamiento de los vuelos de instrucción en la práctica}

Como se anticipó, este estudio tiene su punto de partida en tres casos resueltos por la Corte Suprema de Justicia en los últimos años. Estos son Thieme Magnasco con Servicios Aéreos Romeo Mike Ltda., (Corte Suprema, 15 de noviembre de 2011, rol № 4041-09), Burr y otro con Estado de Chile (Corte Suprema, 26 de octubre de 2011, rol No 8400-09), e Isapre Cruz Blanca S.A., con Carabineros de Chile y otro (Corte Suprema, 23 de noviembre de 2015, rol No 4374-15). Se trata de tres accidentes ocurridos durante vuelos de instrucción en los que la víctima persigue responsabilidad civil, es decir, una reparación por daños y lesiones. En los tres casos los demandantes obtienen sentencia 
favorable. Lo interesante, y que será objeto de este estudio, son los mecanismos por los que se pide y atribuye responsabilidad al demandado. Los tres casos revelan cierta confusión y perplejidad en las víctimas, en los demandados, pero también en la judicatura. Se pierde de vista la relación contractual que da origen al vuelo de instrucción, se atribuye a este contrato un estatuto que no le pertenece, y esto repercute en un inadecuado tratamiento de la responsabilidad especial del Código Aeronáutico. La situación se torna más compleja cuando en el accidente interviene un funcionario público perteneciente a alguno de los órganos mencionados en el artículo 21 de la Ley $N^{\circ} 18.575$, denominada "Ley orgánica de bases generales de la administración del Estado", en adelante también LBGAE.

Los hechos se presentan de la siguiente forma. En Thieme Magnasco con Servicios Aéreos Romeo Mike Ltda., en adelante también Thieme (2011), se rechazan los recursos de casación en la forma y en el fondo interpuestos por la parte demandada, y se condena a la empresa a indemnizar los perjuicios sufridos por el demandante. El demandante, alumno del curso de instrucción, funda su demanda en las heridas de diversa gravedad sufridas como consecuencia del accidente ocurrido durante un vuelo de instrucción realizado en una aeronave de propiedad de la demandada, en el cual, además, fallece el piloto instructor de vuelo. Se pide la resolución del contrato más la indemnización de perjuicios y, en subsidio, la indemnización de perjuicios por responsabilidad extracontractual. El tribunal de primera instancia rechaza tanto la demanda principal como la subsidiaria, sin costas. La Corte de Apelaciones de Santiago rechaza el recurso de casación en la forma interpuesto contra la sentencia de primera instancia. Resolviendo la apelación, revoca, y acoge la demanda sólo en cuanto condena a la demandada a indemnizar parte de los perjuicios solicitados por el demandante, particularmente daño emergente y lucro cesante, con costas. Para imputar responsabilidad a la demandada, la Corte de Apelaciones de Santiago invoca la autoridad del artículo 100 CA, otorgándole carácter objetivo. Para fundamentar su decisión, el tribunal apela a la autoridad de los artículos 142 y 143 CA, aplicables a lesiones o muerte por accidentes ocurridos durante vuelos de transporte aéreo. La parte demandada interpone recursos de casación en la forma y en el fondo. La Corte Suprema rechaza ambos recursos. El primero, porque no se configura la causal invocada. El segundo, porque, a su juicio, no se acusa el quebrantamiento por falsa aplicación de la disposición contenida en el artículo 100 CA, ya que, de acuerdo a la Corte, no se expresa en relación a este artículo, norma decisoria litis de la sentencia, en qué consiste el error de derecho ni se señala de qué modo ese error influyó sustancialmente en lo dispositivo del fallo. 
En Burr y otro con Estado de Chile, en adelante también Burr (2011), se rechaza el recurso de casación en el fondo interpuesto por el Fisco de Chile, resultando definitiva la condena a indemnizar los perjuicios sufridos por los demandantes a causa del accidente ocurrido durante un examen de revalidación de la habilitación de vuelo por instrumentos. Los demandantes en este caso son, por una parte, el alumno, quien solicita la indemnización por las lesiones sufridas a causa del accidente ocurrido durante el mencionado examen; $y$, por otra, el dueño de la aeronave que resultó completamente destruida como consecuencia del accidente. Los actores demandan al Estado por falta de servicio, lo que estaría conectada con la negligencia del inspector de vuelo (piloto examinador), funcionario de la DGAC, quien autorizó la realización del vuelo pese a las condiciones climáticas adversas. El tribunal de primera instancia acoge la demanda interpuesta por el alumno y rechaza la demanda interpuesta por el dueño de la aeronave. La Corte de Apelaciones de Santiago revoca parcialmente la sentencia para acoger también la demanda del dueño de la aeronave, condenando al Fisco a indemnizar el daño emergente y el daño moral. Asimismo, se modifica la condena obtenida por el alumno, desestimando la indemnización del lucro cesante, pero confirmando en lo demás la sentencia. La Corte Suprema rechaza el recurso de casación en el fondo interpuesto en contra de esta sentencia, señalando que cabe aplicar la responsabilidad del Estado por falta de servicio a partir del artículo 2314 CC. En este caso, la condición de funcionario del Estado del inspector de vuelo, dependiente de la DGAC, es el factor que condiciona la responsabilidad civil del Estado por falta de servicio.

En el último caso, Isapre Cruz Blanca S.A., con Carabineros de Chile y otro, en adelante también Isapre (2015), se rechazan los recursos de casación en la forma y en el fondo interpuestos por el Fisco de Chile. El Estado resulta, entonces, condenado a indemnizar los perjuicios en la superficie causados por la caída de una aeronave perteneciente al Club Aéreo de Carabineros de Chile, conjuntamente con la sucesión del capitán de Carabineros que se desempeñaba como instructor de vuelo en el club aéreo de dicha institución, fallecido en el accidente. La demandante es la isapre Cruz Blanca, por subrogación en la acción civil de la víctima, afiliada da la isapre. Una mujer, que se encontraba en la multicancha de Peñalolén, sufrió quemaduras y la pérdida de una pierna a causa de la caída a tierra de la aeronave durante un vuelo de instrucción. Los demandados se defienden oponiendo la excepción de prescripción de la acción fundada en el artículo 175 CA (un año desde el día de los hechos). La excepción es desestimada por tratarse en este caso de una acción de indemnización de perjuicios por responsabilidad extracontractual. Por tanto, el plazo de prescripción del artículo 2332 CC (cuatro años desde la perpetración del acto) no se había cumplido al momento de la notificación de la demanda. Se acoge 
la demanda en todas sus partes, declarando el tribunal que los demandados se encuentran obligados a indemnizar a la actora. En alzada se confirma el fallo. La Corte Suprema rechaza los recursos de casación en la forma y en el fondo interpuestos por la parte vencida, este último fundado en la supuesta infracción de los artículos 2314 y 2322 CC, señalando en su sentencia que el Estado no puede desvincularse de la falta personal de uno de sus agentes, por lo que la acción del funcionario de Carabineros no se encuentra separada del servicio, sino que se comete una falta personal que compromete la responsabilidad estatal.

Como se puede apreciar, todos los accidentes descritos ocurren en el contexto de un vuelo de instrucción. Tanto en Thieme (2011) como en Burr (2011) el explotador de la aeronave es un particular. La diferencia entre estos dos radica en que sólo en el segundo caso el alumno va acompañado en la aeronave por un inspector de vuelo de la DGAC, y no simplemente por un piloto instructor, con licencia de la DGAC. El hecho que pone en marcha la responsabilidad del Estado por falta de servicio en Burr (2011) es, por tanto, la calidad de inspector de vuelo que tiene el examinador bajo cuya autoridad se realiza el vuelo, es decir, de funcionario del Estado. En Isapre (2015) la aeronave pertenece al Club Aéreo de Carabineros de Chile y la indemnización de perjuicios es solicitada por una mujer que no tiene conexión alguna con el vuelo de instrucción en que ocurre el accidente, que sufre daños en la superficie a causa de la caída de la aeronave. Los demandantes dirigen su acción contra el Estado por falta de servicio. La razón es que, más allá del plazo más extenso de prescripción de esta acción, que es de cuatro años (artículo 2332 CC) en vez de uno (artículo $175 \mathrm{CA}$ ), según el artículo $3^{\circ}$ inciso $2^{\circ} \mathrm{CA}$ a las aeronaves del Fisco destinadas a Carabineros de Chile para el ejercicio de sus funciones sólo les son aplicables las normas contenidas en los artículos 52, 53, 57 y 181 CA. Están excluidas, por tanto, del régimen de responsabilidad objetiva por daños en la superficie establecido en los artículos 155 a 160 CA.

Lo expuesto anteriormente levanta la cuestión de si es aplicable el régimen especial del Título IX del Código Aeronáutico (artículos 142 a 175) a los casos de daños, lesiones o muerte en accidentes ocurridos en vuelos de instrucción, que es la cuestión que se aborda a continuación. Esto exige distinguir entre vuelos de instrucción y vuelos de transporte aéreo, específicamente de pasajeros, que es donde parece estar la clave, y que es lo que se hace a continuación.

\section{Los vuelos de instrucción y los vuelos de transporte aéreo de pasajeros}

Para distinguir entre vuelos de instrucción y vuelos de transporte aéreo es necesario tener en cuenta a ciertos actores relevantes en la actividad aeronáutica; y, en especial, en el desarrollo de los vuelos de instrucción. Interesan 
especialmente las figuras del explotador de la aeronave (\$3.1.), la del comandante de la aeronave o piloto al mando (§ 3.2.) y las de los que participan en un vuelo de instrucción (alumno, instructor de vuelo e inspector de vuelo) (\$3.3.). Las atribuciones y responsabilidades de cada uno de los sujetos mencionados permiten determinar quién es la máxima autoridad en un vuelo de instrucción (§3.3.4.) y cómo podría modificarse la responsabilidad si la víctima se expone imprudentemente al daño (§3.3.5.). Todo lo anterior deja en evidencia que los vuelos de instrucción se realizan con objetivos y sujetos distintos, y en cumplimiento de contratos diferentes, a los vuelos de transporte aéreo de pasajeros. Por tanto, como proponemos, el régimen de responsabilidad especial que afecta al transportador (Título IX del CA) no se aplica al responsable de los daños de un vuelo de instrucción (§ 3.4).

\subsection{El dueño o explotador de la aeronave}

En el desarrollo de la actividad aeronáutica intervienen determinados sujetos sin importar el tipo de actividad aérea de que se trate. Entre estos se encuentra el explotador de la aeronave, que, de acuerdo al artículo 99 CA, es la persona que utiliza la aeronave por cuenta propia, con o sin fines de lucro, y que conserva la dirección técnica de la misma. El inciso $2^{\circ}$ de esta norma establece que se presume explotador al propietario de la aeronave. "Esta presunción se desvirtúa mediante el cumplimiento de una formalidad por vía de publicidad, consistente en inscribir el acto o contrato por el cual se transfirió la calidad de explotador en el Registro Nacional de Aeronaves" ${ }^{\prime 3}$. De lo contrario, se aplicará la solidaridad establecida en el artículo 100 CA. En consecuencia, quienes pueden ser explotador de una aeronave son, en primer lugar, su propietario, ya sea que haya pilotado la aeronave o haya designado a un comandante con este objeto; en segundo lugar, el arrendatario de la aeronave, ya que, de acuerdo al artículo 101 inciso $2^{\circ} \mathrm{CA}$, este contrato transfiere la calidad de explotador siempre y cuando se otorgue por escritura pública o instrumento privado autorizado y protocolizado ante notario y, conforme al artículo 99 CA, el instrumento se inscriba en el Registro Nacional de Aeronaves, y, por último, toda aquella persona a la que por algún otro acto se le haya transferido la calidad de explotador y el acto se inscriba en el mencionado registro.

Siguiendo a Mario Folchi, son cuatro los elementos que integran la figura del explotador de la aeronave. A saber ${ }^{4}$ : a) El uso legítimo de la aeronave, ya

3 Barroilhet y díaz (2002), p. 336.

${ }^{4}$ FOLCHI (2015), p. 394. 
sea porque es su propietario o porque ha celebrado algún acto o contrato que lo faculta a utilizar la aeronave, y que se encuentra debidamente inscrito en el Registro Nacional de Aeronaves (artículo $100 \mathrm{CA}$ ). "Y esto es fundamental porque pone de relieve que el explotador tiene la titularidad de un derecho, lo que por un lado garantiza la legitimidad del uso de la aeronave y por el otro, le hace asumir determinadas obligaciones convirtiéndole, en consecuencia, en responsable de los perjuicios que cause por dicho uso" ${ }^{\prime \prime}$. b) El uso de la aeronave por cuenta propia. Es decir que el propio explotador es quien se beneficia con esta actividad, beneficio que no necesariamente es puramente económico (artículo 99 CA). c) La dirección técnica de la aeronave, sea que la aeronave sea pilotada personalmente por el explotador o por un comandante designado por él, quien será el piloto al mando de la respectiva operación aérea (artículo 64 CA), y d) La existencia o no de una finalidad lucrativa. Recordemos que el Código Aeronáutico clasifica a las aeronaves civiles en aeronaves de uso comercial y aeronaves de uso no comercial o privado (artículo 31 inciso $2^{\circ} \mathrm{CA}$ ).

Ahora bien, la DGAC, en ejercicio de las atribuciones que le entrega la Ley № 16.752, Orgánica de la Dirección General de Aeronáutica Civil (artículo 3º, letra h) $)^{6}$ para emitir normas técnicas con el objeto de resguardar la seguridad de la navegación aérea, dictó la Norma DAN-1377 , sobre trabajos aéreos, en la cual dispuso que si el explotador desea realizar cualquier operación de trabajo aéreo, deberá obtener previamente un Certificado de Operador Aéreo Comercial (OAC). La misma norma define operador como el titular de un Certificado de Operador Aéreo Comercial. Por tanto, en la aeronáutica comercial la figura del explotador se identifica con la del operador aéreo comercial. En la aeronáutica no comercial no existe la figura del operador aéreo, que es siempre comercial.

Observando los casos en que se apoya este estudio, se constata que en Thieme (2011) el demandado es operador de la aeronave. En Burr (2011) el demandado es el Estado, un tercero distinto al explotador de la aeronave. En Isapre (2015) el demandado es el Club Aéreo de Carabineros de Chile, explotador de la aeronave, ya que no procede hablar de operador toda vez que nos encontramos en el ámbito de la aeronáutica no comercial. En este último caso, sin embargo, el demandante es un tercero que está en la superficie y resulta lesionado por la caída de la aeronave, es decir, es una persona que no tiene relación contractual con el demandado.

5 FolCHI (2015), p. 394.

6 Ley No 16.752, de 1968.

7 Resolución (DGAC) Ex. № 381, de 2014. 


\subsection{El comandante de la aeronave}

El comandante es el piloto al mando de la aeronave (artículo 65 CA), que puede coincidir o no con la persona del explotador, ya que, como se mencionó, este último puede actuar por sí o a través de comandante designado para la respectiva operación aérea, (artículo 64 CA). En este sentido, el Reglamento DAR-01 reitera lo dispuesto en el Código Aeronáutico definiendo piloto al mando como aquel piloto designado por el explotador o por el propietario de la aeronave en cada operación aérea, para que esté al mando de la aeronave y se encargue de la operación segura de un vuelo o parte de él. Como se puede apreciar, si bien es el comandante quien detenta el control técnico de la aeronave, lo hace en virtud de la designación realizada por el explotador. Sin embargo, en ausencia del explotador, puede ejecutar o celebrar todos los actos imprescindibles para la prosecución del vuelo, en representación de aquél (artículo 69 CA).

Antes de iniciar el vuelo, el comandante debe cerciorarse de que la aeronave esté apta para iniciar la operación y si luego de realizar su revisión personal y control previo estima que la aeronave no está apta para la operación podrá negarse a recibirla (artículo $70 \mathrm{CA}$ ) o no iniciar o suspender el vuelo si a su parecer se encuentra en peligro la seguridad del mismo, debiendo entregar al explotador los fundamentos de la decisión tomada y a la autoridad aérea según corresponda (artículo 68, letra c) CA), debe recabar los informes meteorológicos de su ruta y suspender el vuelo si éstos no arrojaren una predicción favorable. Asimismo, durante el vuelo, el comandante debe adoptar las medidas que estime necesarias para la seguridad de la aeronave, de los pasajeros y de la carga, y cumplir las instrucciones de los servicios de control de tránsito aéreo, salvo que ello fuere peligroso para la seguridad de la aeronave o de las personas a bordo (artículo 67 letras b), c), i) y f) CA). El comandante es el principal responsable de la conducción segura de la aeronave y la única y máxima autoridad a bordo de la aeronave, quien posee facultades disciplinarias sobre su tripulación, autoridad sobre los pasajeros y control total sobre la aeronave y la carga transportada en su caso (artículo 65 CA).

No debe confundirse al explotador o al comandante de la aeronave con el transportador. El transportador es "aquella persona física o jurídica que, contando con la adecuada organización, se compromete a trasladar por sí misma a una persona o cosa desde un lugar a otro, con arreglo a las condiciones estipuladas" $^{8}$, o, como señalan Barroilhet y Díaz, es "la persona que se obliga a conducir pasajeros, equipajes o mercancías de un lugar a otro, a cambio de

${ }^{8}$ Mapelli (1987) p. 88. 
un precio denominado porte o flete aéreo ${ }^{\prime \prime}$. Por lo tanto, cuando hablamos de transportador nos encontramos frente a una de las partes del contrato de transporte aéreo: "Los conceptos de explotador y transportador no necesariamente son idénticos, puesto que -como se distingue entre gestión aeronáutica y comercial-, un explotador puede o no ser, además, transportador"10. Así, en caso de que el explotador sea persona distinta del transportador, ambos responderán solidariamente de las obligaciones que impone el Título IX (artículo 174 inciso $\left.2^{\circ} \mathrm{CA}\right)$.

\subsection{Los intervinientes en los vuelos de instrucción}

Los intervinientes en los vuelos de instrucción son el instructor de vuelo, el alumno y el inspector de vuelo.

\subsubsection{El instructor de vuelo}

El Reglamento DAR-01 define instructor de vuelo en los siguientes términos: persona autorizada por la autoridad aeronáutica para impartir la enseñanza y vigilar el aprendizaje de determinados conocimientos aeronáuticos o la adquisición de cierta pericia en el manejo de aeronaves o del equipo relacionado con éstas.

En consecuencia, el instructor de vuelo es el encargado de enseñar a los alumnos el conjunto de técnicas que se necesitan para pilotar una aeronave en forma eficiente, capacitar a los alumnos para que estén en condiciones de planificar sus vuelos tomando en consideración todos los factores necesarios para la realización de un pilotaje seguro, ejerciendo para esto funciones de instrucción, supervisión y evaluación de pilotos, en tierra y en vuelo. Así, el instructor de vuelo tiene la labor de verificar las aptitudes del alumno teniendo en cuenta todas las medidas necesarias para reducir cualquier riesgo.

Para desempeñar la función de instructor de vuelo, el interesado deberá ser titular de la licencia de piloto comercial o superior, con la habilitación de instructor de vuelo o instructor de vuelo por instrumentos si corresponde (Norma DAN-137.613, sobre instructores de vuelo).

\subsubsection{El alumno}

En una primera aproximación podemos señalar que el alumno, en el caso de los vuelos de instrucción, es aquella persona que busca instruirse

\footnotetext{
${ }^{9}$ Barroilhet y Díaz (2002), p. 362.

10 Barrollhet y Díaz (2002), p. 335.
} 
o perfeccionarse en el arte de volar. De acuerdo al Reglamento DAR-01, se debe distinguir entre alumno-piloto y piloto-alumno: es alumno-piloto tanto el postulante a una licencia de piloto, como el titular de una licencia de alumnopiloto y que va a bordo de una aeronave supervisado por un instructor de vuelo, con el objeto de recibir instrucción de vuelo. En cambio, el piloto-alumno es aquella persona que ya es titular de una licencia de piloto y va a bordo de una aeronave con la única finalidad de recibir instrucción de vuelo. En esta línea, se distingue también el piloto privado y el piloto comercial. La realización del curso de piloto privado es el primer paso para aprender a pilotar un avión; en cambio, la realización del curso de piloto comercial y la posterior obtención de esta licencia permite desempeñarse laboralmente como piloto.

\subsubsection{El inspector de vuelo}

El inspector de vuelo es el funcionario designado por la DGAC que, en representación de la autoridad aeronáutica, se encarga de realizar las pruebas de pericia y los exámenes relativos al otorgamiento, revalidación y renovación de las licencias y habilitaciones aeronáuticas establecidas en el Reglamento DAR-01.

Para efectos de nuestro estudio, debemos señalar que, de acuerdo a la Norma DAN-137, sobre trabajos aéreos, una vez que el alumno finaliza el curso de instrucción, el operador debe presentar a sus alumnos ante la DGAC, órgano dependiente del Ministerio de Defensa Nacional, quienes deberán rendir los exámenes necesarios (teórico y práctico) para obtener las licencias y habilitaciones que en el caso correspondan. Para esto, se debe acompañar la carpeta de progreso de la instrucción teórica y del vuelo, confeccionada por el instructor a cargo del curso; la bitácora personal de vuelo elaborada por el alumno debidamente certificada por el operador, y la calificación final otorgada por el instructor de vuelo que acredite que el alumno está apto para rendir el examen teórico y de vuelo ante la DGAC (Norma DAN-137.619, sobre presentación de los alumnos a la DGAC).

\subsubsection{El comandante en los vuelos de instrucción}

En los vuelos de instrucción surge la pregunta respecto de quién detenta la calidad de máxima autoridad a bordo de la aeronave y, por lo tanto, es el principal responsable de la conducción segura de la aeronave. Esto porque si bien es el alumno quien se sienta al lado izquierdo de la aeronave y opera los mandos de esta durante el tiempo de vuelo, obedece las instrucciones del instructor de vuelo o del inspector de vuelo según corresponda. En cuanto a este punto resulta interesante analizar la causa Burr (2011), en la que el Fisco interpone un recurso de casación en el fondo en contra de la sentencia dictada por la 
Corte de Apelaciones de Santiago, indicando como primera infracción la de los artículos 64, 65, 67 letras i) y f) y 68 letra c) del Código Aeronáutico debido a que, en la especie, el piloto de la aeronave era el propio demandante y, por lo tanto, a su juicio, el comandante de la misma. En consecuencia, afirma que la obligación de adoptar las medidas necesarias para la seguridad del vuelo recaía sobre el demandante, quien, además, tenía la facultad de no iniciar o interrumpir el vuelo si a su juicio se encontraba en peligro la seguridad del mismo. En la causa se fijan como hechos, entre otros, que el piloto-alumno se sometía a un examen de revalidación de su habilitación de vuelo por instrumentos a cargo del piloto examinador, que pilotaba privado de visión toda vez que llevaba puesta una careta que sólo le permitía ver los instrumentos, y que el vuelo se realizó en condiciones meteorológicas adversas. La Corte de Apelaciones de Santiago estableció que de los antecedentes podía deducirse que el accidente se debió a la conducta imprudente adoptada por el piloto examinador, quien decidió efectuar el vuelo pese a las condiciones meteorológicas imperantes.

La Corte Suprema, resolviendo el recurso de casación, señaló que el conjunto de normas infringidas según la recurrente, tienen por objeto prevenir la responsabilidad para el comandante de la aeronave, pero ello sólo para "vuelos normales" (cons. quinto), y en este caso, el actor, si bien pilotaba la aeronave, se sometía a una evaluación ante un inspector de vuelo, y además volaba privado de visión, por lo que la aeronave se encontraba bajo el control del examinador. En consecuencia, de acuerdo a la Corte Suprema, las normas citadas regulan una situación distinta a la de los vuelos de instrucción, por lo que no se presenta la infracción reclamada toda vez que quien tenía el deber de adoptar las medidas necesarias para reducir riesgos y evitar el accidente era, en este caso, el inspector de vuelo. A nuestro parecer, la Corte Suprema entrega un razonamiento correcto, ya que en la práctica es el instructor de vuelo o el inspector de vuelo, según quien sea la persona que acompaña al alumno, la máxima autoridad a bordo de la aeronave, quien se encuentra constantemente entregando instrucciones al alumno al mando de la aeronave. Por lo tanto, sobre aquél recae el deber de adoptar todas las medidas necesarias para que el alumno conduzca de forma segura la aeronave, considerando el tipo de alumno de que se trate de acuerdo a la distinción entregada y evitar cualquier riesgo durante el vuelo. De esta forma, las normas contenidas en los artículos 64 y siguientes CA, no son aplicables a los casos en los que quien pilota la aeronave desde su asiento izquierdo es un alumno-piloto o un piloto-alumno, ya que aunque en el caso que se trate de una persona con experiencia en vuelo, siempre estará bajo la supervisión e instrucciones del piloto instructor o del inspector de vuelo en su caso. 


\subsubsection{La exposición imprudente al daño en los vuelos de instrucción}

Cabe preguntarse si en el caso de un piloto experimentado, como es por ejemplo un piloto comercial, existe una exposición imprudente al daño si éste accede a ser evaluado en condiciones climáticas adversas o en otro tipo de circunstancias que indiquen que el vuelo debe cancelarse o suspenderse. Esto, porque puede ocurrir que en un determinado accidente exista una concurrencia de causas. "Son casos en que el resultado dañoso tiene su origen (causa) en la actuación conjunta de agente y víctima, y cada una de las conductas es condición (adecuada) indispensable para la producción de la integridad del daño"11.

En Burr (2011), el Fisco afirma en su defensa que el alumno demandante se expuso imprudentemente al daño. La Corte de Apelaciones sostiene en su sentencia que no aparece acreditado que el demandante, alumno en el vuelo, se haya expuesto imprudentemente al daño. Agrega que, incluso, existen presunciones en sentido contrario, ya que el alumno habría advertido al inspector de vuelo sobre las condiciones meteorológicas existentes en ese momento; sin embargo, fue compelido a volar pese a dicha advertencia. Se desprende de la sentencia, que el examen tenía por objeto la revalidación de la habilitación de vuelo por instrumentos. La víctima, por tanto, ya era titular de la licencia de piloto ${ }^{12}$.

Ahora, cabe preguntarse si debe evaluarse de la misma manera si existió exposición imprudente al daño en el caso de un alumno-piloto, que en el de un piloto-alumno, o en el caso de un piloto privado que en el de un piloto comercial. Se afirma que existe un deber o carga de autocuidado que recae en la víctima. Entonces, "el deber de cuidado respecto de los demás también se aplicaría a la víctima para sí misma y respondería, de igual manera, a la necesidad de conducirse con la prudencia que los hombres emplean ordinariamente en sus actos o negocios, tanto en sus acciones como en sus omisiones" ${ }^{\prime 13}$. Por lo tanto, habrá que realizar un juicio de reproche para determinar si hubo una exposición imprudente al daño para luego determinar en qué medida intervino en la cadena causal que produjo el resultado dañoso.

Si bien la culpa se aprecia en abstracto, "esto es, comparando la conducta del agente con la de un hombre prudente colocado en su misma situación"114 se deben tomar en consideración todas las circunstancias externas que rodean a

\footnotetext{
11 Medina (2003), p. 191.

12 De acuerdo a los registros de la DEAC la víctima era piloto privado desde el 3 de diciembre de 1981 y el accidente ocurrió el 4 de diciembre de 2002.

13 Bahamondes y Pizarro (2012), p. 42.

14 Alessandri (1943), pp. 173-174.
} 
este sujeto. Por lo tanto, la conducta se compara con aquella que habría tenido un hombre prudente de la misma profesión u oficio, puesto en el mismo tiempo y lugar, sin atender a aspectos personales. En este sentido, parece ser que las circunstancias que rodean a un alumno-piloto pueden ser muy distintas a las de un piloto-alumno, especialmente si éste ya es titular de una licencia de piloto comercial. En esta línea, si bien sabemos que en Burr (2011), tal como se señaló, el alumno ya era titular de una licencia de piloto privado, a la Corte de Apelaciones le bastó para descartar la exposición imprudente al daño el hecho de haber advertido al inspector de la DGAC sobre el estado del clima. Considerando la experiencia del piloto-alumno, su mera advertencia del mal estado del clima no parece suficiente para desechar por entero su exposición imprudente al daño.

\subsection{Diferente naturaleza y régimen de responsabilidad de los vuelos de transporte aéreo}

\subsubsection{Responsabilidad civil del transportador}

El Código Aeronáutico establece un régimen especial de responsabilidad objetiva hasta el tope de 4.000 UF en caso de lesiones o muerte de cada pasajero en vuelos de transporte aéreo. En efecto, el artículo 142 dispone que, en virtud del contrato de transporte, el transportador sea obligado a indemnizar los daños causados con motivo u ocasión del transporte, en la forma y dentro de los límites establecidos en el Código. Asimismo, el artículo 143 inciso $1^{\circ}$, refiriéndose al transporte aéreo de pasajeros, dispone que el transportador sea obligado a indemnizar las lesiones o muerte causadas a los pasajeros durante su permanencia a bordo de la aeronave o durante las operaciones de embarque o desembarque. En esta línea, el artículo 144 establece que la indemnización en este caso estará limitada a una suma que no excederá de 4.000 UF por muerte o lesión de cada pasajero, dándose a las partes la posibilidad de estipular una suma superior a la indicada. Ahora bien, si se pretende obtener una indemnización mayor al tope establecido en la ley, la víctima, de acuerdo al artículo 172 CA, debe probar la culpa o dolo del transportador, del explotador o de sus dependientes cuando éstos actuaren durante el ejercicio de sus funciones. Es por esta razón que se dice que el Código Aeronáutico consagra un régimen de responsabilidad en dos estratos o capas. En la primera de ellas rige un régimen de imputación objetiva hasta el tope de 4.000 UF. En la segunda, a partir de dicho tope, rige un régimen de imputación subjetiva en el que la víctima está obligada a demostrar la imputabilidad del demandado (transportador, explotador o sus dependientes). 
Así, los topes indemnizatorios contenidos en el Código Aeronáutico tienen una función fundamental, cual es fomentar la realización y desarrollo de la actividad, asegurando que el transportador no deba responder ilimitadamente de los perjuicios que pueda causar su actividad. Esto es de toda lógica, ya que "la aeronavegación, por tener lugar en la atmósfera, está sometida a lo que se denomina riesgos aeronáuticos, cuyas consecuencias dañinas son potencialmente tan nefastas, que si el transportista, como cualquier otro contratante ordinario, tuviere que indemnizar uno a uno los perjuicios sufridos por cada usuario, se tornarían prácticamente utópicas las expectativas de una rentabilidad económica en la industria en cuestión" ${ }^{\prime 15}$. Como consecuencia de lo anterior, el transportador estará en condiciones patrimoniales de responder por el daño causado. En esta línea, siguiendo a José Miguel Lecaros, los límites indemnizatorios "son sólo topes de responsabilidad destinados a delimitar el nivel de riesgo financiero del transportista; en ningún caso constituyen una presunción. Por ende el afectado no queda eximido de la necesidad de probar la existencia del daño y la cuantía del perjuicio" ${ }^{\prime 16}$. Sin embargo, el actuar negligente o doloso del transportador traerá como consecuencia la pérdida del beneficio del límite indemnizatorio. Así, el Código Aeronáutico, si bien por un lado, se encarga, en determinados casos, de dar a la responsabilidad un carácter objetivo con la finalidad de asegurar a la víctima una indemnización razonable, por otro, establece topes indemnizatorios en razón de la magnitud de los daños que pueden ocasionarse en el ejercicio de esta actividad, de manera de atenuar el impacto del régimen de imputación de responsabilidad objetiva para no desincentivar el desarrollo de la actividad aeronáutica.

Para establecer si las normas contenidas en los artículos 142 y siguientes CA son aplicables en caso de muerte o lesiones sufridas por un alumno a causa de un accidente ocurrido durante un vuelo de instrucción en una aeronave civil de uso comercial, primero debemos determinar si el vuelo de instrucción remunerado puede ser considerado como un tipo de transporte aéreo. Esto, porque dichas normas fueron pensadas para ser aplicadas a estos vuelos, tal como se desprende del capítulo en el que están contenidas, denominado: "De la responsabilidad en el transporte aéreo" (Capítulo I, del Título IX CA, artículos 142 a 154); y, de no ser aplicables, debemos resolver si es posible dar aplicación a estas normas por analogía. Si no es posible aplicar estas normas a los vuelos de instrucción, será necesario identificar el régimen de responsabilidad aplicable a estos casos. Este problema no surge respecto de los vuelos de instrucción en

\footnotetext{
15 Hananías (2003), p. 356.

16 Lecaros (2012), p. 96.
} 
aeronaves civiles de uso privado, ya que resulta claro que en este caso no puede existir contrato de transporte aéreo. Éste constituye por esencia una actividad lucrativa desarrollada en aeronaves de uso comercial.

Para efectos de determinar si el vuelo de instrucción remunerado constituye un tipo de transporte aéreo, debemos señalar que el Código Aeronáutico en el artículo 93 se refiere a la aeronáutica no comercial como aquella que tiene por objeto desarrollar actividades de vuelo sin fines de lucro, tales como la instrucción, recreación o deporte, teniendo prohibida la realización de servicios de transporte o trabajos aéreos remunerados. En cambio, el artículo 95 CA se refiere a la aeronáutica comercial como aquella que tiene por objeto la realización de vuelos de transporte aéreo de pasajeros o cosas y de trabajos aéreos, con fines de lucro. Una diferencia importante entre la aviación de uso privado y la aviación de uso comercial, y que puede tener enormes consecuencias prácticas, es que, en virtud del decreto ley $\mathrm{N}^{\circ} 2.564$, de 1979, sólo se exige la contratación de seguros a las aeronaves pertenecientes a la aeronáutica comercial. En consecuencia, la Junta Aeronáutica Civil (en adelante, también, JAC) sólo está facultada para establecer y controlar los requisitos de seguros a las aeronaves de uso comercial (artículo $1^{\circ}$, D.L. No 2.564).

El contrato de transporte aéreo es definido en el artículo 126 CA, en los siguientes términos: contrato de transporte aéreo es aquel en virtud del cual una persona, denominada transportador, se obliga, por cierto precio, a conducir de un lugar a otro, por vía aérea, pasajeros o cosas ajenas y entregar éstas a quienes vayan consignadas. En términos similares, Ferrer define específicamente el contrato de transporte aéreo de pasajeros como "el acuerdo de voluntades celebrado entre un transportista y un pasajero en virtud del cual las partes asumen las siguientes obligaciones principales: el transportista, la de trasladar al pasajero y a su equipaje en las condiciones pactadas por vía aérea y en una aeronave; el pasajero la de pagar el precio del traslado"17. Es necesario agregar a esta definición que el traslado debe hacerse en condiciones seguras, toda vez que en este caso existe una obligación de seguridad o cuidado inherente al contrato. En este sentido, el artículo $4^{\circ}$ letra c) del Reglamento de Transporte Aéreo de Pasajeros ${ }^{18}$, en adelante también D.S. № 307, dispone que los empresarios públicos de transporte aéreo estarán obligados a transportar al pasajero y su equipaje con la diligencia debida entre los puntos convenidos.

En cambio, de acuerdo al artículo 95 CA los servicios de trabajos aéreos consisten en la explotación de cualquier actividad comercial distinta al traslado

17 Ferrer (2013), p. 27.

18 D.S. [Defensa] No 307, de 1972. 
de pasajeros o cosas, por medio de aeronaves. En esta línea, el Reglamento DAR-06 define trabajo aéreo como una operación, distinta al traslado de pasajeros o cosas, en el cual la aeronave es utilizada para prestar servicios especializados. Por lo tanto, el servicio de trabajo aéreo se define en términos negativos. En efecto, debe entenderse por tal toda actividad con fines de lucro que no consista en el transporte aéreo de pasajeros o de carga. Así, el Reglamento DAR-06 realiza una clasificación no taxativa de los trabajos aéreos, entre los cuales encontramos: aplicaciones aéreas (ya sean agrícolas, de extinción de incendios, tratamiento de nubes, etc.), observación, investigación, fotografía aérea y aerofotogrametría, prospección y patrullaje aéreo, construcción, publicidad, ambulancia y traslado de heridos e instrucción de vuelo remunerada a bordo de aeronaves (Volumen IV, Capítulo 2.1, Reglamento DAR-06). En consecuencia, no queda más que concluir que los vuelos de instrucción remunerados son una clase de trabajo aéreo. El objeto de cualquier trabajo aéreo dice relación con el desarrollo de una actividad diferente al transporte aéreo, lo que no significa que llevar a cabo dicho trabajo no pueda traer aparejado algún tipo de traslado con el objeto de desarrollar la actividad de que se trate, pero esta circunstancia no le otorga el carácter de transporte aéreo.

\subsubsection{Sentido y alcance del artículo 100 del Código Aeronáutico}

El primer estrato del régimen de responsabilidad establecido en el Código Aeronáutico para ciertas hipótesis del transporte aéreo de pasajeros establece, como se mencionó, un sistema de imputación de responsabilidad objetiva con tope de indemnización, por lo que se prescinde de la culpa o dolo como factor de imputación. Así las cosas, si no concurre eximente alguna de responsabilidad, la víctima del daño tendrá la certeza de que obtendrá una determinada indemnización por el daño causado; y si pretende una indemnización mayor al tope establecido por el legislador, deberá acreditar la culpa o dolo del transportador, del explotador o de sus dependientes, cuando éstos actuaren dentro del ejercicio de sus funciones (artículo $172 \mathrm{CA}$ ).

Ahora bien, en cuanto a la norma invocada como decisoria litis en Thieme (2011), pareciera ser que el artículo 100 CA, ubicado en el Título VII del Capítulo I de dicho cuerpo legal, que también es aplicable a los vuelos de instrucción toda vez que se refiere al explotador sin restringirse al contrato de transporte aéreo, consagra la responsabilidad objetiva del propietario y del explotador de la aeronave, porque utiliza la expresión "cualquier daño". En efecto, el citado

artículo dispone: "El propietario de una aeronave es responsable, solidariamente con el explotador, de cualquier daño que ella produzca, a menos que el acto o contrato mediante el cual se transfiere la calidad de explotador, se inscriba en el Registro Nacional de Aeronaves, caso en el cual el propietario queda liberado de responsabilidad civil". Sin embargo, no debemos olvidar que, nuestro 
ordenamiento jurídico se construye sobre la base de la responsabilidad subjetiva $y$, tal como señala Barros, "no existe en el derecho chileno una norma que establezca una categoría general que comprenda distintos grupos de casos sujetos a este régimen de responsabilidad"19. Por lo tanto, la responsabilidad objetiva es excepcional en nuestro sistema, debiendo en consecuencia estar establecida expresamente en la ley. De hecho, cuando el Código Aeronáutico ha querido dar carácter objetivo a la responsabilidad del explotador o del transportador, lo ha hecho expresamente, estableciendo además ciertos topes indemnizatorios. En consecuencia, no es posible concluir que el artículo 100 CA consagre un régimen de imputación de responsabilidad objetiva, ya que, por una parte, la norma contenida en este artículo no se opone expresamente al régimen general de responsabilidad por culpa, y, por otra, porque no sigue la técnica utilizada por el legislador en el Código Aeronáutico en cuanto a la fijación de topes indemnizatorios en cada uno de los casos en que establece responsabilidad de carácter objetivo para atenuar su impacto. Sin embargo, puede afirmarse que el artículo 100 CA contempla un supuesto de responsabilidad indirecta o vicaria, ya que si el propietario de la aeronave es una persona distinta del explotador y se acredita la culpa del explotador, el propietario deberá responder solidariamente con el explotador, sin que sea necesario realizar un juicio de reproche respecto de aquél, salvo que haya transferido la calidad de explotador con las exigencias que impone la ley, caso en el que quedará eximido de responsabilidad.

Así las cosas, esta norma no tiene por objeto sustraer al propietario o explotador de la aeronave del régimen general de responsabilidad civil, sino que lo que busca es identificar como legitimado pasivo de la obligación de indemnizar los daños que se causen con ocasión de la actividad aeronáutica, al propietario y al explotador de la aeronave, si son personas distintas, norma que al ser de aplicación general resulta aplicable a cualquier actividad aérea, sea ésta relativa a la aeronáutica civil o a la aeronáutica comercial.

\section{El régimen aplicable a los vuelos de instrucción}

El régimen de responsabilidad civil aplicable a los daños, lesiones o muerte en vuelos de instrucción es el de la responsabilidad contractual (artículos 1489 y 1547 CC). Si el accidente ocurre por negligencia del inspector de la DGAC, o de algún funcionario público en el ejercicio de sus funciones, se despliega, además, la responsabilidad del Estado por falta de servicio, por la vía del artículo 2314 CC y leyes especiales. A continuación se examina la aplicación de este sistema a la responsabilidad contractual del explotador de una aeronave civil ( $\S$

19 Barros (2017), p. 446. 
4.1) y, en particular, su aplicación al caso Thieme (2011) (§ 4.2.). Termina esta sección con un análisis de la responsabilidad subsidiaria del Estado si interviene un funcionario público (§ 4.3.) y la legitimación de los sucesores del alumno que muere en un vuelo de instrucción (§ 4.4.).

\subsection{La responsabilidad contractual del explotador}

\subsubsection{La contratación de vuelos de instrucción}

En relación a la contratación de vuelos de instrucción remunerados (aeronáutica comercial), ésta se realiza por el consentimiento del operador aéreo, por una parte, y un alumno-piloto o piloto-alumno, por la otra. Los vuelos de instrucción remunerados se realizan, por tanto, en cumplimiento de un contrato. Por este contrato, el operador aéreo, se obliga, como persona natural o jurídica, a impartir la instrucción teórica y práctica que el alumno necesita para obtener una licencia de piloto o una determinada habilitación por parte de la DGAC. El objeto del contrato es un hecho complejo, integrado por varias obligaciones, el servicio de instrucción teórica y práctica en las técnicas de la aeronavegación. El contrato tiene como contraprestación un precio. Reúne, por tanto, todas las características de un contrato de arrendamiento o prestación de servicios remunerados (artículo 2006 y siguientes CC).

En cuanto a la instrucción perteneciente a la aeronáutica no comercial (artículo 93 CA), ésta también se realiza por el consentimiento del explotador de una aeronave, en este caso un club aéreo, por una parte, y de un alumnopiloto o piloto-alumno (socio del club aéreo), por la otra. Los clubes aéreos son corporaciones de derecho privado que tienen por objeto la práctica deportiva y el uso y fomento de la navegación aérea en todas sus formas (artículo 94 inciso $1^{\circ} \mathrm{CA}$ ). Folchi sostiene que "no cabe duda que la relación que se establece entre el alumno que asiste a clases de pilotaje en un aeroclub y este último es de naturaleza contractual" 20 , cuestión que no cambia el carácter del club aéreo, ya que respecto del socio existe un contrato asociativo que lo vincula con la entidad respectiva. De todo lo dicho anteriormente se concluye que los vuelos de instrucción se realizan en cumplimiento de contratos que no están especialmente regulados en el CA. El Código Aeronáutico tampoco contempla un régimen de responsabilidad especial aplicable a los vuelos de instrucción. Por tanto, conforme a las normas del mismo cuerpo legal, es obligatorio remitirse al derecho supletorio general, es decir, al Código Civil. En este sentido, el artículo $6^{\circ}$ CA dispone: en lo no previsto en este Código ni en los convenios o tratados internacionales aprobados por Chile, se aplicarán las normas del

${ }^{20}$ FolCHI (2015), p. 163. 
derecho común chileno, los usos y costumbres de la actividad aeronáutica y los principios generales del derecho.

Los convenios o tratados internacionales aprobados por Chile se refieren a servicios de transporte aéreo internacional, es decir, aquellos que se prestan entre dos o más puntos ubicados en el territorio de Estados diferentes, aunque se efectúen escalas dentro del territorio de un mismo Estado, o aquellos que se realizan entre dos puntos del territorio nacional, cuando se haya previsto una escala intermedia en otro Estado (artículo 97 CA), (hoy principalmente el Convenio de Montreal de 199921).

Los vuelos de instrucción aérea realizados dentro del territorio nacional se sujetan, por tanto, a la legislación interna, es decir, a las normas del "derecho común chileno, los usos y costumbres de la actividad aeronáutica y los principios generales del derecho" (artículo $6^{\circ} \mathrm{CA}$ ). Los usos y costumbres de la actividad aeronáutica y las normas del derecho común chileno son los que permiten reconstruir las obligaciones de las partes. Como se señaló anteriormente, al alumno no le son aplicables las normas que regulan la figura del comandante de la aeronave (artículos 64 a $75 \mathrm{CA}$ ), ya que si bien el alumno está sentado al lado izquierdo de la aeronave y, por lo tanto, es quien pilota la aeronave durante el tiempo de vuelo, el alumno no es designado como comandante por el explotador ni tampoco es la máxima autoridad durante el vuelo, ya que durante el curso de instrucción, el alumno sigue las directrices del instructor de vuelo. El instructor de vuelo debe vigilar el aprendizaje del alumno y es el responsable de la seguridad en la conducción de la aeronave, debiendo adoptar durante el tiempo de vuelo todas las medidas necesarias para evitar cualquier riesgo que exceda el riesgo normal o razonablemente aceptado.

\subsubsection{La obligación de seguridad del vuelo}

Como se señaló, entre el alumno y el explotador, sea éste una persona natural o jurídica que explota una aeronave de uso comercial, o un club aéreo, existe una relación contractual. De esta relación emanan determinadas obligaciones para el explotador, entre éstas, la obligación de seguridad. Esta obligación es inherente a este tipo de actividad, que se desarrolla en virtud del contrato, por lo que no importa si la obligación fue expresada o no, toda vez que los contratos deben ejecutarse de buena fe, por lo que no obligan sólo a lo que en ellos se expresa, sino también a todas las cosas que emanan precisamente de la obligación o que por la ley o la costumbre pertenecen a ella (artículo 1546 CC). En esta línea, "si existe una relación contractual se ha entendido en forma más o

21 D.S. [Resoluciones exteriores] № 281, de 2009. 
menos compartida que concurre una obligación de seguridad en todo contrato en que existe un riesgo para la integridad física o síquica del acreedor ${ }^{\prime \prime 22}$.

Quien presta el servicio de instrucción de vuelo y, en general, quien desarrolla este tipo de actividad, conoce los riesgos propios de ésta y, por tanto, está Ilamado a evitar posibles daños que pueda causar en el desarrollo de su actividad. En consecuencia, y tal como explica Vidal, la especie de contratos en los que se encuentran aquellos de contenido personal "impone al deudor el deber de seguridad o protección sobre la persona del acreedor, garantizándole su interés de conservación de manera que es previsible e indemnizable el daño moral que se siga de su lesión"23. Esta obligación de seguridad, que recae en el explotador y que puede extraerse del principio de buena fe contractual, también puede construirse a partir de la normativa propia de los trabajos aéreos y, particularmente, de los vuelos de instrucción remunerados. Esta normativa exige al operador que la aeronave cumpla con los requisitos exigidos por la DGAC para llevar a cabo el trabajo aéreo de que se trate (Norma DAN-137.137, sobre requisitos de las aeronaves). En esta línea, el Capítulo D de esta norma, referente al mantenimiento, establece que el operador es primariamente responsable del mantenimiento de la aeronavegabilidad de su aeronave, de que la aeronave se mantenga en condición aeronavegable, de que el certificado de aeronavegabilidad de la aeronave se encuentre vigente y que el mantenimiento de la aeronave sea realizado por las personas establecidas en la Norma DAN-43 (Norma DAN137.301, sobre responsabilidad del operador). Asimismo, el Capítulo B, relativo a las reglas generales de operación, dispone que el operador autorizado para realizar operaciones relativas a trabajos aéreos deberá asegurar que su personal conozca las leyes y normativas aeronáuticas vigentes en Chile relacionadas con las funciones que realizan, y, en lo que concierne a los pilotos, deberá asegurar, además, que éstos conozcan lo prescrito para las zonas que deben sobrevolar y para los aeródromos y emplazamientos eventuales que hayan de usar (Norma DAN-137.101, sobre observación de leyes, reglamentos y normativas aeronáuticas). En cuanto a los vuelos de instrucción en particular, el Capítulo G, sobre instrucción de vuelo, exige, entre otras cosas, que la aeronave esté provista por lo menos de dos asientos, con un sistema duplicado de controles primarios de vuelo y frenos y respecto a los controles de potencia, los que deben ser fácilmente alcanzables y operables tanto por el alumno como también por el instructor o examinador (Norma DAN-137.605, sobre aeronaves). También establece que quien quiere desempeñarse como instructor de vuelo, debe ser

22 Boetsch (2011), p. 115.

${ }^{23}$ VIDAL (2014), p. 352. 
titular de la licencia de piloto comercial o superior, con la habilitación de instructor de vuelo o instructor de vuelo por instrumentos si corresponde (Norma DAN-137.613, sobre instructores de vuelo). Por último, no se debe olvidar la definición de instructor entregada por el Reglamento DAR-01: aquella persona autorizada por la autoridad aeronáutica para impartir la enseñanza y vigilar el aprendizaje de determinados conocimientos aeronáuticos o la adquisición de cierta pericia en el manejo de las aeronaves o del equipo relacionado con éstas. En consecuencia, a partir de la Norma DAN-137, sobre trabajos aéreos, no queda más que concluir que de la instrucción de vuelo emana un deber de seguridad y vigilancia, por lo que el explotador debe cerciorarse de que quienes utilicen su aeronave cumplan con las exigencias impuestas por la normativa vigente. En este sentido, en el hecho o culpa del deudor se debe comprender el hecho o culpa de las personas por quienes fuere responsable (artículos 44, 1679,2320 CC). Así las cosas, como en sede contractual la culpa del deudor se presume (1547 CC), será el explotador el Ilamado a probar, por una parte, que la aeronave se encontraba en condiciones óptimas de funcionamiento y, por otra, que el instructor de vuelo designado cumplió con el deber de vigilancia y cuidado que le era exigible, pudiendo solicitar que se le exonere de toda responsabilidad por caso fortuito o fuerza mayor.

\subsubsection{Acción, legitimados, procedimiento y plazo}

La acción para exigir indemnización de perjuicios por lesiones o muerte por un accidente ocurrido durante un vuelo de instrucción corresponde a la víctima, que es contraparte en el contrato de instrucción de vuelo en el caso de una escuela de vuelo, o es el socio del club aéreo, con el que existe un contrato asociativo, es decir, el alumno-piloto o piloto-alumno (artículo 1556 CC). Estas acciones se tramitan, en todo caso, conforme a las reglas del juicio ordinario. El plazo que tiene la víctima para deducir su acción es de cinco años desde el incumplimiento que causa el daño (artículo 2515 CC). En cuanto a la forma de solicitar la indemnización de perjuicios luego de un accidente ocurrido durante el curso de instrucción de vuelo, cabe preguntarse, si es necesario solicitar la resolución del contrato más indemnización de perjuicios (artículo 1489 CC), o bien la indemnización puede solicitarse de forma autónoma en virtud del incumplimiento de una obligación de hacer (artículo 1553 regla 3a CC). A nuestro juicio, lo correcto es solicitar la indemnización de perjuicios por incumplimiento de una obligación de seguridad de manera independiente 
invocando directamente el artículo 1489 CC, cuestión que excede el objeto de nuestro estudio ${ }^{24}$.

\subsection{Aplicación de un pretendido régimen de imputación objetiva en Thieme (2011)}

En Thieme (2011), tal como se esbozó anteriormente, el demandante solicita como demanda principal la resolución del contrato con indemnización de perjuicios y, en subsidio, la indemnización de perjuicios por responsabilidad extracontractual. Por su parte, la demandada solicita el rechazo de las acciones deducidas en su contra y, en subsidio, pide que se rebaje considerablemente el monto de la demanda a una cantidad equitativa, justa y razonable.

La Corte de Apelaciones de Santiago revoca la sentencia de primera instancia. Por una parte, rechaza la resolución del contrato, lo que se justifica, ya que la naturaleza de la obligación imposibilitaba restituir a las partes al estado anterior; pero, por otra, acoge la indemnización de perjuicios invocando el artículo 100 CA, norma a la que le otorga carácter objetivo, para atribuir responsabilidad a la demandada. En esta línea, luego de citar esta norma, la Corte señala que los artículos 142 y 143 CA, relativos a la responsabilidad en el transporte aéreo, discurren sobre la misma idea en el caso de lesiones o muerte causadas al pasajero y agrega que, en este caso, también es útil tener a la vista la forma en que los convenios internacionales tratan la responsabilidad de los dueños de la aeronave y del explotador a fin de tener un marco de referencia al respecto, afirmando que uno de los principales avances del Convenio de Montreal es que consagra la responsabilidad objetiva del transportista hasta un determinado monto (hoy 113.100, derechos especiales de giro en caso de muerte o lesiones por cada pasajero) (cons. noveno). A partir de lo anterior, concluye que la tendencia actual en materia de accidentes aéreos que causan lesiones o muerte a personas es construir la responsabilidad sobre bases distintas a las bases tradicionales que establece nuestro Código Civil (cons. décimo).

Este razonamiento puede explicarse por anomalías en el itinerario procesal del juicio. Al recibir la causa a prueba, el juez de letras fija como segundo punto sustancial y controvertido: "la existencia de un hecho negligente o culposo cometido por la demandada y en la afirmativa, en qué consistió". Sin embargo, resolviendo posteriormente una reposición, lo modifica, eliminando la exigencia de probar la imputabilidad del demandado, cuya existencia se presume (artículo 1547 CC). El hecho controvertido queda fijado así: "existencia de un hecho o hechos que causaron daño al actor, en la afirmativa, autor o perpetrador de ellos

24 Sobre la autonomía de la acción de indemnización de perjuicios, véase Contardo (2014), pp. 261269; PizarRo y Vidal (2010), pp. 301-302. 
en su caso". Es por esta razón que, según se desprende del fallo de casación, los hechos que quedaron demostrados durante las instancias son, entre otros, que el mantenimiento y la revisión previa de la aeronave se encontraban sin observaciones; que el peritaje de la aeronave determinó que el motor y sus componentes no presentaron ningún tipo de fallas; que el peritaje del combustible arrojó que éste cumplía con las características normales de gasolina, y que el piloto instructor de vuelo tenía experiencia suficiente en el material usado (cons. quinto). Asimismo, se determinó que la causa probable del accidente fue la detención del motor de la aeronave con posterioridad al despegue, debida a una interrupción del flujo de combustible, y que contribuyó a este evento el probable desconocimiento del piloto-alumno de las advertencias que hace el Manual del Avión (Norma DAN-137) con respecto a evitar maniobras abruptas que pueden provocar una interrupción momentánea del flujo de combustible, y del procedimiento a seguir en estos casos.

Como se señaló, el tribunal de primera instancia rechaza tanto la demanda principal como la subsidiaria, sin costas. Así las cosas, pareciera ser que al tribunal le basta la serie de peritajes que indicaban que la aeronave se encontraba en buen estado y que el instructor contaba con experiencia suficiente para liberar de responsabilidad al demandado, apoyándose además en la causa probable del accidente y en la contribución a ésta por parte del alumno. Sin embargo, en virtud del régimen de responsabilidad aplicable en este caso, tocaba al explotador probar que la obligación de seguridad inherente a este contrato fue cumplida, ya que, como quedó establecido, las normas relativas al comandante de la aeronave (artículo 64 y siguientes CA) no son aplicables al alumno de un vuelo de instrucción. El instructor de vuelo tenía el deber de adoptar todas las medidas necesarias para la conducción segura de la aeronave y evitar cualquier riesgo durante el tiempo de vuelo. La maniobra imprudente del piloto-alumno sólo podía ser usada como argumento de una posible acumulación de causas del accidente aéreo. La responsabilidad del vuelo la tenía, por tanto, la escuela de vuelo demandada en el juicio. Sin embargo, es posible que el tribunal luego de modificar el punto segundo de prueba, no agrega como hecho a probar la diligencia o cumplimiento del deber de seguridad del demandado.

Por su parte, la Corte de Apelaciones sostiene que, al modificarse el punto de prueba y eliminarse como hecho sustancial y controvertido el elemento culposo, el demandante centró su actividad probatoria sólo en la existencia del daño y su autor. Afirma que esta cuestión probatoria, produjo indefensión al demandante (pese a que la carga probatoria de la culpa no recaía en el demandante, sino en la demandada) y en ella se centra por tanto el recurso de apelación (cons. quinto y sexto). Así, la Corte de Apelaciones para imputar responsabilidad al demandado invoca el artículo 100 CA, dando a entender que 
esta norma consagra una responsabilidad de imputación objetiva, en virtud de la cual no es necesario demostrar la imputabilidad del demandado, sino sólo el hecho y su relación de causalidad con el resultado dañoso.

En contra de esta sentencia, la demandada interpone recursos de casación en la forma y en el fondo. La Corte Suprema rechaza ambos recursos. El primero, porque no se configura la causal invocada. El segundo, porque a su juicio no se expresa en qué consiste el error de derecho ni se señala de qué modo ese error influyó sustancialmente en lo dispositivo del fallo. Como se puede apreciar, si bien la Corte de Apelaciones revoca la sentencia y en consecuencia acoge la demanda, la fuente de responsabilidad de la demandada era el incumplimiento de la obligación de seguridad, inherente al contrato. Cuestión en la que tal vez la Corte no fundó su desición debido a que es probable que no se haya dado al demandado la posibilidad de probar su diligencia a través de la fijación del punto de prueba respectivo, optando así por invocar el artículo 100 CA y otorgarle carácter objetivo. La escuela de vuelo estaba obligada a responder por el hecho o culpa de las personas por quienes era responsable (artículo 1679 CC), es decir, del instructor de vuelo. La demandada era explotadora de la aeronave y conservaba la dirección técnica de la misma (artículo 99 CA), recayendo sobre ella la obligación de responder de los daños (artículo 100 CA), sin perjuicio de que posteriormente pudiera repetir en contra el instructor de vuelo.

\subsection{La responsabilidad subsidiaria del Estado por la acción de un funcionario de la DGAC}

Como se señaló en su oportunidad, a diferencia de los instructores, los inspectores de vuelo, son funcionarios dependientes de la DGAC encargados de verificar que el alumno cuente con los conocimientos y destrezas necesarias para convertirse en piloto, ya sea privado o comercial, u obtener las habilitaciones que correspondan. En consecuencia, en virtud del Capítulo 2.5.4 del Reglamento DAR-01, los inspectores designados por la DGAC, están facultados para administrar las pruebas de pericia y los exámenes atingentes al otorgamiento, revalidación y renovación de las licencias y habilitaciones aeronáuticas establecidas en el mismo reglamento. Por lo tanto, una vez terminado el curso de instrucción, el alumno es acompañado durante el examen práctico por un inspector de vuelo de la DGAC. No existe vínculo contractual alguno entre el alumno y el inspector de vuelo o entre el explotador y el inspector de vuelo, pese a que el vuelo de evaluación se realiza en la aeronave perteneciente al explotador o en la aeronave que el alumno desee utilizar, la que no es de propiedad de la DGAC, y respecto de la cual el inspector de vuelo no es su explotador, ya que no existe acto alguno que le transfiera la calidad de tal. 
En Burr (2011) el accidente ocurre durante un examen de revalidación de la licencia de vuelo ante un inspector de la DGAC, donde se condena al Estado por falta de servicio. En cuanto a la naturaleza de este tipo de responsabilidad, Barros explica que "la responsabilidad por falta de servicio no es estricta u objetiva en un sentido propio, porque no basta acreditar que el daño fue causado por la acción u omisión del demandado, (en este caso de la Administración), sino supone un juicio de valor acerca del nivel y calidad del servicio que era exigible del municipio o del órgano de la administración" ${ }^{25}$. En otras palabras, es incorrecto sostener que la responsabilidad por falta de servicio es una responsabilidad objetiva, ya que no basta probar el daño y la relación de causalidad, sino que además se debe probar la falta de servicio, factor de imputación en este tipo de responsabilidad. Para esto se debe comparar el servicio que fue prestado en la práctica, y respecto del cual se reclama, con un servicio normal, tomando en consideración los medios con que el órgano respectivo contaba al momento de prestar el servicio. Sin embargo, como señala el mencionado autor, tampoco es una responsabilidad subjetiva, ya que, al ser la responsabilidad de una persona jurídica, no es requisito probar la culpa del funcionario que en concreto causó el daño. No obstante, si bien es una responsabilidad directa, muchas veces el funcionario podrá ser individualizado y será precisamente su conducta la que deje en evidencia la falta de servicio, pudiendo resultar ambos (funcionario público y Estado) solidariamente responsables en virtud de lo establecido en el artículo 2317 CC.

El artículo 42 LBGAE, dispone: Los órganos de la Administración serán responsables del daño que causen por falta de servicio. No obstante, el Estado podrá repetir en contra del funcionario que hubiere incurrido en falta personal. Sin embargo, por expresa disposición del artículo $21 \mathrm{LBGAE}$, el título segundo de esta ley, en el que se encuentra el artículo 42 recién citado, no es aplicable a las Fuerzas Armadas, a las Fuerzas de Orden y Seguridad, a los gobiernos regionales, a las municipalidades, al Consejo Nacional de Televisión y a las empresas públicas creadas por ley. Esto produce un problema en cuanto al régimen de responsabilidad aplicable en estos casos, ya que, conforme al artículo $21 \mathrm{LBGAE}$, a estas instituciones sólo les es aplicable el artículo $4^{\circ}$ LBGAE, que fue establecido como un principio general. Por lo tanto, se hace necesario determinar si puede aplicarse la responsabilidad por falta de servicio a los casos de accidentes aéreos en los que interviene un inspector de vuelo de la DGAC, órgano dependiente de la Fuerza Aérea de Chile (en adelante también $\mathrm{FACH}$ ), o en los que la aeronave es pilotada por un funcionario público de alguno de los órganos mencionados en el artículo citado. La tendencia de

25 Barros (2017), p. 486. 
nuestra jurisprudencia en los últimos años ha sido aplicar a estas instituciones la responsabilidad por falta de servicio por la vía del artículo 2314 CC. Así, por ejemplo, en Burr (2011), donde se condena al Estado a indemnizar los perjuicios, la demandada señala en el recurso de casación en el fondo interpuesto que fueron infringidas, entre otras, las normas contenidas en los artículos $4^{\circ}$ y $21 \mathrm{LBGAE}$. La Corte Suprema rechaza el recurso señalando que las instituciones exceptuadas de la aplicación del título segundo de la LBGAE, quedan sujetas al derecho común, y por tanto a las reglas generales de la responsabilidad extracontractual. Por lo que, a su entender, es posible aplicar la responsabilidad por falta de servicio por la vía del artículo 2314 CC. "En efecto, al Estado como a los otros entes públicos administrativos pueden serle aplicadas de manera diversa las normas del Título XXXV del Código Civil, sin que esto implique una errada interpretación de las mismas" 26 . En Isapre (2015), el Fisco invoca como normas infringidas las contenidas en los artículos 2314 y 2322 CC. La Corte Suprema, resolviendo del recurso, se manifiesta de la misma forma que en Burr (2011), y agrega que la noción de falta de servicio se debe complementar con la noción de falta personal. "Dicha falta personal compromete la responsabilidad del Estado cuando no se encuentra desprovista de vínculo con la función, lo que ocurre cuando ella se ha cometido en ejercicio de la función o con ocasión de la misma" ${ }^{27}$.

En conclusión, a juicio de los sentenciadores en los fallos aludidos, en los casos de accidentes en que el piloto examinador pertenezca a la DGAC, y el vuelo sea realizado en ejercicio de sus funciones, es posible atribuir al Estado responsabilidad por falta de servicio a partir del artículo 2314 CC.

\subsection{Legitimación de los sucesores del alumno que muere en un vuelo de instrucción}

Se discute si los herederos pueden ejercer la acción de indemnización de perjuicios del daño moral conforme a las reglas de responsabilidad contractual. Esta discusión emerge en todos aquellos casos en que existía un contrato celebrado entre la víctima que ha fallecido y el explotador de la aeronave. La conclusión a la que se llegue adquiere importancia en la práctica toda vez que, de estimarse que los herederos deben demandar los perjuicios conforme a las reglas de la responsabilidad extracontractual, deberán probar la culpa del agente del daño.

${ }^{26}$ Corte Suprema, rol № 8400-09, de 26 de octubre de 2011.

27 Corte Suprema, rol № 4374-15, de 23 de noviembre de 2015. 
"En Chile, en general se ha sostenido que por el daño patrimonial experimentado por el pasajero antes de morir, pueden demandar sus herederos sujetándose a las reglas de la responsabilidad contractual, toda vez que el derecho a la reparación (en carácter de un derecho a una reparación por incumplimiento) se transmite a los herederos en sus calidades de continuadores legales" ${ }^{28}$, cuestión que es analogable a los vuelos de instrucción. Sin embargo, se discute sobre la transmisibilidad del derecho a solicitar indemnización de perjuicios por daño moral (discusión existente no sólo en el ámbito aeronáutico).

En un extremo encontramos autores que no admiten la transmisibilidad de este derecho. Así, por ejemplo, Domínguez señala que "siempre existen dos obstáculos para admitir justificadamente la transmisibilidad: el fundamento personalísimo del daño a reparar y la finalidad perseguida con la indemnización que no se avienen con un ejercicio de la acción por quienes no han sufrido el daño" ${ }^{\prime 29}$. Otra parte de la doctrina afirma que "la acción que se dirige a la reparación de los daños morales, constituiría un crédito desde el momento mismo de la producción del daño a causa del eventus damni, y es precisamente en ese momento en que se produce la lesión susceptible de apreciación pecuniaria y la posibilidad de demandarse su reparación -en rigor, su compensación- ${ }^{\prime \prime 30}$. En apoyo de esta postura también se afirma que la ley no prohíbe expresamente la transmisibilidad de esta acción y que, en virtud del principio de la reparación integral del daño, esta acción debe transmitirse, de lo contrario se dejaría sin reparación el daño sufrido por la víctima, sin que importe quien sea el que posteriormente goce del producto de dicha reparación.

Existe una postura intermedia que distingue si la muerte se produjo de forma inmediata o si, por lo contrario, tardó en producirse, sosteniendo que la inmediatez de la muerte trae como consecuencia que el derecho no se alcance a radicar en el patrimonio de la víctima, no existiendo en ese caso transmisión alguna. Así, de acuerdo a esta postura "si la víctima directa fallece en el acto, no transmite a sus herederos derecho a demandar perjuicios morales, pues su angustia no existió debido a la inmediatez del deceso; podrán reclamar, eso sí, los gastos de entierro si fueron sufragados con dineros del causante; así como los daños causados a sus bienes" ${ }^{\prime \prime 1}$.

28 LeCAros (2012), p. 141.

29 Domínguez (2004), p. 513.

30 Pérez (2010), p. 125.

31 TAMAYO (2017), p. 1196. 


\section{Régimen de responsabilidad por daños causados a terceros en la superficie}

Queda, por último, analizar la situación de los daños, lesiones o muerte causados a terceros en la superficie debido a la acción de una aeronave que realiza un vuelo de instrucción, o de lo que de ella cae o se desprende.

El Capítulo II CA se denomina "De la responsabilidad por daños a terceros en la superficie". Sin embargo, al igual que en otras legislaciones, el Código Aeronáutico, no establece qué debe entenderse por tercero perjudicado. De acuerdo a la teoría general del contrato, terceros siempre son los que no son parte en un contrato. Los terceros que resultan víctimas por muerte, lesiones o daños por la acción de una aeronave o de objetos que se desprenden de ella no tienen relación contractual alguna con el explotador que causa el daño.

En cuanto al régimen de responsabilidad por daños en la superficie, el Código Aeronáutico al igual que en el transporte aéreo, consagra una responsabilidad especial en dos estratos. Por una parte, el artículo 155 CA dispone que el explotador debe indemnizar los daños que se causen a las personas o cosas que se encuentren en la superficie, por el solo hecho de que emanen de la acción de una aeronave en vuelo, o por cuanto de ella caiga o se desprenda. El explotador sólo puede eximirse de responsabilidad acreditando que ha sido privado del uso de la aeronave por un acto de autoridad pública, que los daños fueron provocados como consecuencia directa de un acto de guerra o de un conflicto armado, de un acto de sabotaje o con ocasión de un apoderamiento ilícito de la aeronave (artículo 156 CA). El artículo 158 CA establece topes indemnizatorios en razón del peso de la aeronave que causa el daño. Pero, por otra parte, y al igual que en los otros casos en los que el Código Aeronáutico consagra este tipo de responsabilidad, la prueba del dolo o culpa del explotador o de sus dependientes que hayan actuado en ejercicio de sus funciones hace perder el beneficio del tope indemnizatorio en virtud del ya citado artículo 172 CA. Además, el Código Aeronáutico contempla un caso de responsabilidad vicaria, ya que el artículo 157 CA establece que si la aeronave fue usada por una persona distinta del explotador, ambos deben responder solidariamente de los daños causados conforme a los topes y condiciones establecidos en el Código Aeronáutico, salvo que el explotador acredite que adoptó todas las medidas necesarias para evitar el uso de la aeronave, o que le fue imposible hacerlo, prueba en virtud de la cual será eximido de responsabilidad.

En esta línea, el artículo 86 CA prohíbe arrojar objetos sólidos, líquidos o gaseosos desde una aeronave en vuelo, exceptuando aquellos casos previstos en el mismo Código o que se den en el marco de actividades permitidas por la autoridad aeronáutica. Por lo que deberán indemnizarse los daños causados por cualquier pieza, materia o elemento que caiga o se desprenda de la aeronave, 
por los gases o sustancias que emanen de ésta, por el ruido de los motores, etc., siempre y cuando, de acuerdo al artículo $155 \mathrm{CA}$, la aeronave se encuentre en vuelo. En este sentido, el artículo 28 CA establece desde y hasta que momento debemos entender que una aeronave se encuentra en vuelo. Así, este artículo dispone que: Para los efectos de este Código, se entiende que una aeronave se encuentra en vuelo desde el momento en que comienza a moverse con el objeto de despegar, hasta detenerse una vez finalizado el vuelo.

Entonces, el elemento determinante para considerar que una aeronave está en vuelo no es el movimiento propiamente tal, sino más bien la finalidad con la que se realiza el movimiento, ya que si la aeronave no se encuentra en el aire desarrollando la actividad de que se trate (transporte, instrucción, fumigación, etc.), el movimiento que haga debe consistir en "movimiento con el objeto de despegar o movimiento hasta detenerse tras finalizado el vuelo, de modo que si hay daños ocasionados por la acción de la aeronave mientras estaba en movimiento para ser conducida al lugar de mantención, esos daños no quedan incluidos en la norma" ${ }^{\prime \prime 2}$, tampoco quedan incluidos aquellos daños causados por piezas o elementos que caen o se desprenden de una aeronave que se encuentra detenida. Todos los casos que no tengan cabida en la norma citada, deberán regirse por el derecho común en virtud del artículo $6^{\circ} \mathrm{CA}$.

Ahora bien, cabe destacar que el régimen de responsabilidad establecido en el Código Aeronáutico por daños en la superficie no se restringe solamente al contrato de transporte aéreo, como ocurre en los casos de daños sufridos por el pasajero a bordo de la aeronave o durante las operaciones de embarque o desembarque, o de daños o pérdida de equipaje o mercadería, sino que este régimen de responsabilidad es aplicable a cualquier tipo de vuelo, sea privado o comercial, se dedique a servicios de transporte aéreo o a cualquier trabajo aéreo, toda vez que la norma hace referencia al explotador de la aeronave, sin restringirse al transportador. No obstante lo anterior, el inciso segundo del artículo $3^{\circ} \mathrm{CA}$ dispone que a las aeronaves del Fisco destinadas a Carabineros de Chile para el ejercicio de sus funciones propias, sólo les serán aplicables los artículos 52, 53, 57 y 181 CA.

En Isapre (2015), a diferencia de los casos anteriores, la víctima no iba a bordo de la aeronave, sino que se encontraba en la multicancha de Peñalolén, lugar en el que cayó la aeronave en la que se realizaba un vuelo de instrucción. Tampoco mantenía con el explotador vínculo contractual alguno. La aeronave pertenecía al Club Aéreo de Carabineros de Chile y el instructor de vuelo era funcionario de dicha institución. La demanda es dirigida en contra de Carabineros de Chile y de la sucesión del carabinero instructor de vuelo. La

32 Lecaros (2012), p. 303. 
demandante invoca como fundamento de derecho las normas contenidas en los artículos 2314 y siguientes CC. Por su parte, los demandados, en el recurso de casación interpuesto, afirman que fueron vulnerados por falta de aplicación los artículos $4^{\circ}$ y $13 \mathrm{CC}$, desatendiéndose el principio de especialidad al no aplicar las normas del Código Aeronáutico y considerar que se estaba juzgando una acción indemnizatoria propia del Código Civil. En esta línea, alegan que también fue infringido por falta de aplicación el artículo $6^{\circ} \mathrm{CA}$, que consagra el principio de especialidad de las normas contenidas en el Código Aeronáutico, debiendo, a su juicio, haberse acogido la excepción de prescripción en virtud del artículo 175 CA, que dispone: Las acciones establecidas en este título (Título VIII, De los contratos aeronáuticos) prescribirán en el plazo de un año contado desde el día de los hechos, desde el día en que la aeronave llegó a destino o desde que el transporte fue interrumpido, según el caso.

El tribunal de primera instancia desestima la excepción de prescripción, ya que sostiene que el supuesto en el que se funda es errado, toda vez que en la especie se ejerció una acción de indemnización de perjuicios por responsabilidad extracontractual, por lo tanto, el plazo de prescripción era de cuatro años, el que no se había cumplido al momento de la notificación de la demanda. Por su parte, la Corte de Apelaciones agrega respecto de este punto que no cabe la alegación de especialidad formulada, puesto que la demandante, en vez de invocar una responsabilidad de carácter objetivo, invocó el régimen de responsabilidad extracontractual, fundado en las normas de derecho común, y sostiene que en el caso en estudio no se invocó la ocurrencia de un "accidente aéreo", sino el obrar dañoso de quien pilotaba la aeronave y la responsabilidad que le cabía a su empleador por los daños causados, asumiendo la mayor carga probatoria que impone este régimen. Por último, la Corte Suprema rechaza el recurso de casación en el fondo. La Corte sostiene que el artículo 175 CA no resulta aplicable al presente caso porque dicha norma está vinculada exclusivamente con la responsabilidad objetiva regulada en el Código Aeronáutico, conclusión que, a su juicio, se ve refrendada por lo establecido en el artículo 172 CA. Asimismo, agrega que el artículo 175 CA no puede ser invocado como norma decisoria litis toda vez que, en virtud del artículo $3^{\circ}$ inciso $2^{\circ} \mathrm{CA}$, el régimen especial de responsabilidad contenido en el Código Aeronáutico no es aplicable a las aeronaves destinadas a Carabineros de Chile en el ejercicio de sus funciones (cons. vigésimo segundo).

En consecuencia, puede deducirse que, en caso de daños en la superficie causados por una aeronave civil (artículo 31 CA), existe un cúmulo de regímenes aplicables (con excepción de las aeronaves del Fisco destinadas a Carabineros de Chile en el ejercicio de sus funciones), pudiendo la víctima optar entre el régimen objetivo de responsabilidad consagrado en el artículo 
155 y siguientes CA o el régimen de responsabilidad del derecho común, ya sea para atribuir responsabilidad extracontractual o responsabilidad por falta de servicio por la vía del artículo 2314 CC, según corresponda. Así, si bien en virtud del régimen establecido en el Código Aeronáutico no es necesario realizar análisis alguno sobre la conducta del agente para atribuir responsabilidad, la acción prescribe en el plazo de un año. Y, por el otro lado, si bien la acción para perseguir la responsabilidad extracontractual prescribe en el plazo de cuatro años contado desde el hecho dañoso, existen mayores dificultades probatorias, ya que no basta con acreditar únicamente el daño y el nexo causal. En conclusión, las aeronaves del Fisco destinadas a Carabineros de Chile en el ejercicio de sus funciones, quedan excluidas del régimen de responsabilidad regulado en el Código Aeronáutico para daños causados a terceros en la superficie. En esta línea, de acuerdo a la Directiva de Organización y Funcionamiento de la Prefectura Aérea de Carabineros de $\mathrm{Chile}^{33}$, dictada por el general director de Carabineros de Chile, esta institución cuenta con una prefectura aérea que corresponde a una repartición de orden y seguridad especializada encargada de realizar funciones institucionales, operativas y de apoyo a través de la utilización de tecnologías y recursos aeronáuticos, para lo que debe capacitar y entrenar a su personal de pilotos y mecánicos y evaluar la competencia profesional de los mismos. En conclusión, en aquellos casos, que intervenga una aeronave de propiedad de Carabineros de Chile en ejercicio de sus funciones, necesariamente deberá recurrirse al derecho común para perseguir responsabilidad.

Ahora bien, no obstante la uniformidad del régimen aplicable en caso de daños causados a terceros en la superficie, toda vez que éste, como se mencionó, no se restringe solamente al contrato de transporte aéreo, en la práctica pueden darse dificultades a la hora de obtener la debida indemnización de perjuicios cuando la aeronave que causa los daños es una aeronave de uso no comercial o privado. Esto se debe a que sólo se exige la contratación de seguros a las aeronaves pertenecientes a la aeronáutica comercial, por lo que la JAC sólo está facultada para controlar y exigir el cumplimiento de contratación de seguros a las aeronaves de uso comercial (artículo $1^{\circ}$ D.L. $N^{\circ}$ 2.564). Por lo tanto, si bien la víctima de daños en la superficie causados por una aeronave no comercial se ve favorecida con este régimen de responsabilidad, puede que el explotador de la aeronave, por ejemplo un club aéreo o un particular, no haya contratado un seguro de daños y no tenga en su patrimonio el dinero suficiente para responder por los perjuicios, pese a existir una sentencia favorable al actor.

${ }^{33}$ Orden General № 2.333, de 2015. 


\section{Conclusiones}

Los casos de lesiones o muerte sufridos por el alumno en accidentes ocurridos en vuelos de instrucción están excluidos del régimen especial de responsabilidad en dos estratos establecido en el Código Aeronáutico para ciertas hipótesis del transporte aéreo. Este régimen, en el caso del transporte aéreo de pasajeros, fue establecido para regular la responsabilidad del transportador por la muerte o lesiones causadas a los pasajeros durante su permanencia a bordo de la aeronave o durante la operación de embarque o desembarque (artículo 143 CA). En este sentido, el vuelo de instrucción remunerado es una actividad diferente al servicio de transporte aéreo, ya que constituye un tipo de trabajo aéreo (Reglamento DAR-06), operación distinta al traslado de pasajeros o cosas, en el cual la aeronave es utilizada para prestar servicios especializados. En consecuencia, el vuelo de instrucción no es una especie de transporte aéreo. Tampoco es posible afirmar que este tipo de vuelos incluye transporte aéreo de pasajeros en virtud del traslado que se realiza, ya que en el vuelo de instrucción remunerado no existe el pago del pasaje entendido como contraprestación a la obligación de traslado y además, por regla general, no existe un traslado desde un punto de origen a otro punto distinto.

La norma contenida en el artículo 100 CA tiene un objeto distinto al que fue señalado por la Corte Suprema en Thieme (2011). Lo que busca esta norma es identificar, como legitimados pasivos de la obligación de indemnizar los daños que se causen con ocasión de la actividad aeronáutica, al propietario y al explotador de la aeronave si éstas son personas distintas, existiendo respecto del propietario una especie de responsabilidad vicaria. En esta línea, el Código Aeronáutico no determina el régimen de responsabilidad aplicable a los vuelos de instrucción, por lo que debe acudirse al régimen de derecho común (artículo $6^{\circ} \mathrm{CA}$ ).

Tanto los vuelos de instrucción remunerados, como aquellos no remunerados realizados en clubes aéreos se sujetan al régimen de responsabilidad contractual de derecho común.

Respecto de los primeros, existe un contrato de prestación de servicios y respecto de los segundos existe un contrato asociativo que vincula al socio con el club aéreo. Por lo tanto, el explotador tendrá la carga de probar el cumplimiento de la obligación de seguridad inherente a esta actividad, que se desarrolla a partir del contrato (artículo 1546 CC). La acción para exigir indemnización de perjuicios se tramita conforme a las reglas del juicio ordinario. El plazo será de cinco años desde el incumplimiento que causa el daño, pudiendo demandarse la indemnización de perjuicios de forma autónoma fundado en el artículo 1489 CC. 
Los accidentes que se producen durante el examen ante el inspector de vuelo, funcionario de la DGAC, o durante el curso de instrucción cuando el instructor de vuelo es un funcionario público, se sujetan al régimen de responsabilidad por falta de servicio a partir del artículo 2314 CC, ya que nuestros tribunales de justicia han sostenido que las instituciones exceptuadas de la aplicación del título segundo de la $\mathrm{LBGAE}$, entre éstas, la $\mathrm{FACH}$, órgano del que depende la DGAC, quedan sujetas al derecho común, y por tanto a las reglas generales de la responsabilidad extracontractual. Respecto a la exposición imprudente al daño por parte de la víctima (artículo 2330 CC), el juicio de reproche de carácter objetivo que debe hacerse en este caso, será diferente dependiendo si la víctima era un alumno-piloto o un piloto-alumno, o un piloto privado o un piloto comercial, ya que las circunstancias externas que rodean a uno y a otro son distintas y deben tomarse en consideración. La acción para exigir indemnización de perjuicios se tramita conforme a las reglas del juicio ordinario. El plazo será de cuatro años desde la perpetración del acto.

Las normas que regulan la figura del comandante de la aeronave no son aplicables al alumno de un curso de instrucción. Estas normas fueron pensadas para "vuelos normales", y en los vuelos de instrucción, si bien el alumno opera los mandos de la aeronave, sigue las instrucciones del instructor de vuelo o del inspector de vuelo, según quien sea la persona que acompañe al alumno. Son éstos los responsables de la seguridad en la conducción de la aeronave. Por lo tanto, el demandado, no puede defenderse sosteniendo que el deber de seguridad recae en el propio alumno que pilota la aeronave (artículo 64 y siguientes CA). Aquél sólo podrá exonerarse de la responsabilidad si logra probar que actuó diligentemente, o que concurrió una hipótesis de caso fortuito o fuerza mayor (artículo 1547 CC).

Si una aeronave civil o lo que de ella cae o se desprende causa daños a terceros en la superficie, éstos pueden invocar el régimen especial de responsabilidad consagrado en el Código Aeronáutico, ya que aquí el Código no distingue el tipo de actividad desarrollada por la aeronave o a quién pertenecía. Sin embargo, quedan excluidas, en virtud del artículo $3^{\circ}$ inciso segundo CA, las aeronaves del Fisco destinadas a Carabineros de Chile para el ejercicio de sus funciones propias. En consecuencia, por regla general existe un cúmulo de regímenes aplicables, pudiendo optarse entre el régimen especial de responsabilidad consagrado en el Código Aeronáutico, en el que no es necesario realizar análisis alguno sobre la conducta del agente, pero cuya acción prescribe en el plazo de un año (artículo $175 \mathrm{CA}$ ), o el régimen común de responsabilidad, en donde, si bien hay mayores dificultades probatorias, la acción prescribe en el plazo de cuatro años, contado desde el hecho dañoso. Sin embargo, pese a la uniformidad que parece existir en la aplicación del régimen de responsabilidad 
consagrado en el Código Aeronáutico a los casos de daños causados a terceros en la superficie, lo cierto es que en la práctica pueden presentarse problemas en cuanto al cobro de la indemnización de perjuicios cuando la aeronave que causa los daños es una aeronave no comercial, porque sólo se exige la contratación de seguros a las aeronaves pertenecientes a la aeronáutica comercial. Así las cosas, no existe justificación alguna para eximir a las aeronaves de uso privado de la obligación de contratar seguros cuando éstas están sometidas al mismo régimen especial de responsabilidad en caso de daños en la superficie.

\section{BiBLIOGRAFÍA CITADA}

AlESSANDRI Rodríguez, Arturo (1943): De la responsabilidad extracontractual en el derecho civil chileno (Santiago, Imprenta Universitaria).

Bahamondes Oyarzún, Claudia y Pizarro Wilson, Carlos (2012): “La exposición de la víctima al daño: desde la culpabilidad a la causalidad", en: Revista de Derecho de la Pontificia Universidad Católica de Valparaíso (Año XXXIX, No 39), pp. 39-52.

Barroilhet Acevedo, Claudio y Díaz Díaz, Alejandro (2002): Derecho de transporte (Santiago, Libromar Ltda.), tomo I.

BARros Bourie, Enrique (2007): Tratado de responsabilidad extracontractual (Santiago, Editorial Jurídica de Chile).

Boetsch Gillet, Cristián (2011): La buena fe contractual (Santiago, Editorial Jurídica de Chile).

Contardo González, Juan (2014): "Independencia de la acción de perjuicios en sede contractual. Corte Suprema, Primera Sala (civil), 10 de septiembre de 2013, rol 885-2013", en: Revista Chilena de Derecho Privado (№ 22), pp. 261-269.

Domínguez, Ramón (2004): "Sobre la transmisibilidad de la acción por daño moral", en: Revista Chilena de Derecho (Vol. 31, № 3), pp. 493-514.

FERRER TAPIA, Belén (2013): El contrato de transporte aéreo de pasajeros: sujetos, estatuto y responsabilidad (Madrid, Dykinson).

Folchi, Mario O. (2015): Tratado de derecho aeronáutico y política de la aeronáutica civil (Buenos Aires, Astrea), tomos I y II.

Hananías Castillo, Rodrigo (2003): La responsabilidad civil en el transporte aéreo de mercancías (Santiago, Editorial Jurídica La Ley).

Lecaros SánChez, José Miguel (2012): La responsabilidad civil y la actividad aeronáutica (Santiago, Librotecnia). 
MAPELLI LóPEZ, Enrique (1987): Régimen jurídico del transporte (Madrid, Ministerio de Justicia, Secretaría Técnica).

Medina Alcoz, María (2003): La culpa de la víctima en la producción del daño extracontractual (Madrid, Dykinson).

Pérez, Alfonzo (2010): "A favor de la transmisibilidad de la acción de daño moral", en: Revista Derecho y Humanidades (Vol. 2, № 16), pp. 119-132.

PizARRo Wilson, Carlos y VIDAl Olivares, Álvaro (2010): Incumplimiento contractual, resolución e indemnización de daños (Bogotá, Editorial Universidad del Rosario), pp. 301-312.

Vidal Olivares, Álvaro (2014): "Criterios para la procedencia de la indemnización del daño moral por incumplimiento contractual. Una mirada desde el derecho contractual", en: De la Maza Gazmurı, Íñigo et al., Estudios de derecho de contratos. Formación, cumplimiento e incumplimiento (Santiago, LegalPublishing-Thomson Reuters), pp. 337-364.

\section{NORMAS JURÍDICAS CITADAS}

Ley № 18.916, aprueba el Código Aeronáutico. Diario Oficial, 8 de febrero de 1990.

Ley N No 18.575, Orgánica Constitucional de Ley de Bases Generales de la Administración del Estado. Diario Oficial, 5 de diciembre de 1986.

Ley N ${ }^{0} 16.752$, Orgánica de la Dirección General de Aeronáutica Civil. Diario Oficial, 17 de febrero de 1968.

Decreto con Fuerza de Ley $N^{0}$ 1, fija el texto refundido, coordinado y sistematizado del Código Civil, entre otras materias. Diario Oficial, 30 de mayo de 2000.

Decreto Supremo No 307 (Ministerio de Defensa), sobre contrato de transporte aéreo. Diario Oficial, 31 de octubre de 1972.

Decreto Ley $N^{\circ} 2.564$, dicta normas sobre aviación comercial, modifica los decretos con fuerza de ley $\mathrm{N}^{\circ}$ s. 221 de 1931 y 241 de 1960 y deroga los preceptos que señala. Diario Oficial, 22 de junio de1979.

Decreto Supremo № 52 (Ministerio de Defensa), Reglamento sobre operación de aeronave. Diario Oficial, 20 de julio de 2002.

Decreto Supremo No 11 (Ministerio de Defensa), Reglamento sobre licencias al personal aeronáutico. Diario Oficial, 21 de abril de 2004.

Resolución (Exenta) № 381 (DGAC), sobre trabajos aéreos. Diario Oficial, 11 de octubre de 2014. 
Decreto Supremo № 261 (Ministerio de Relaciones Exteriores), promulga el Protocolo de Montreal $\mathrm{N}^{\circ} 4$, que modifica el convenio para la unificación de ciertas reglas relativas al transporte aéreo internacional. Diario Oficial, 16 de enero de 2009.

Orden General № 2.333 (Carabineros de Chile, Dirección General), Directiva de organización y funcionamiento de la Prefectura Aérea de Carabineros de Chile. Boletín Oficial de Carabineros de Chile, 20 de abril de 2015.

\section{JURISPRUDENCIA CITADA}

Isapre Cruz Blanca S.A. con Carabineros de Chile y otro (2015): Corte Suprema, 23 de noviembre de 2015, rol № 4374-15 (acción de indemnización de perjuicios) en: http://basejurisprudencial.poderjudicial.cl/.

Thieme Magnasco con Servicios Aéreos Romeo Mike Ltda. (2011): Corte Suprema, 15 de noviembre de 2011, rol № 4041-09 (acción de resolución de contrato e indemnización de perjuicios) en: Microjuris MJJ30022.

Burr y otro con Estado de Chile (2011): Corte Suprema, 26 de octubre de 2011, rol No 8400-09 (acción de indemnización de perjuicios) en: Documento11 http://hasejurisprudencial.poderjudicial.cl/. 